This item was submitted to Loughborough's Research Repository by the author.

Items in Figshare are protected by copyright, with all rights reserved, unless otherwise indicated.

\title{
The interaction between temperature and hypoxia on the rate of neuromuscular fatigue development
}

\section{PLEASE CITE THE PUBLISHED VERSION}

http://dx.doi.org/10.1249/01.mss.0000466118.29837.67

\section{PUBLISHER}

American College of Sports Medicine

VERSION

AM (Accepted Manuscript)

\section{PUBLISHER STATEMENT}

This work is made available according to the conditions of the Creative Commons Attribution-NonCommercialNoDerivatives 4.0 International (CC BY-NC-ND 4.0) licence. Full details of this licence are available at: https://creativecommons.org/licenses/by-nc-nd/4.0/

\section{LICENCE}

CC BY-NC-ND 4.0

\section{REPOSITORY RECORD}

Lloyd, Alex, Margherita Raccuglia, S.G. Hodder, and George Havenith. 2019. "The Interaction Between Temperature and Hypoxia on the Rate of Neuromuscular Fatigue Development". figshare. https://hdl.handle.net/2134/18157. 


\section{THE INTERACTION BETWEEN TEMPERATURE AND HYPOXIA ON THE RATE OF NEUROMUSCULAR FATIGUE DEVELOPMENT}

AUTHOR BLOCK: Alex Lloyd, Simon G. Hodder, Margherita Raccuglia, George Havenith. Loughborough University, Loughborough, United Kingdom.

ABSTRACT: High altitude is often comprised of both hypoxia and thermal stress. Independent exposures to these stressors are suggested to impair neuromuscular function and thereby performance; however relatively little research has investigated neuromuscular responses to hypoxia and thermal stress in combination. PURPOSE: To determine the interactive effect of temperature and hypoxia on neuromuscular fatigue rates and subsequent task failure in the knee extensors. METHODS: Six (preliminary data) active males were exposed to three ambient temperatures $\left(5,23,43^{\circ} \mathrm{C}\right.$; COL, NEU, HOT, respectively) at two levels of oxygen concentration (0.21, $0.13 \mathrm{FIO2}$; CON, HYP, respectively). Following a 40-min rest period, participants carried out dynamic knee extension exercise at a fixed intensity $(34 \pm 10 \mathrm{~W})$ until task failure. At every 2 -min interval, participants performed a single maximal isometric voluntary contraction with twitch interpolation (0.2-ms, square wave doublet; $125 \pm 22 \mathrm{~mA}$ ) to discern the rate of voluntary and peripheral fatigue development. Regression analysis was used to define the relationship between time and various fatigue markers. To test for significance, a three-way (time $x$ FIO2 $x$ temperature) repeated measures ANOVA was used. RESULTS: Rectal, muscle and mean skin temperature were all significantly $(p<0.05)$ affected by HOT and COL ambient temperatures. The rate of peripheral fatigue development (resting twitch force) over time significantly increased during HOT $(p<0.05)$, COL $(p<0.05)$ and HYP $(p<0.001)$. Peripheral fatigue rates were further increased during combined HYP-COL and HYP-HOT; however the results showed no interaction ( $p=0.8 \& 0.4$ respectively). Similarly, independent exposure to HOT $(p<0.05)$, COL $(p<0.01)$ and HYP $(p<0.05)$ significantly reduced exercise time $(34 \pm 17,23 \pm 5$ and $54 \pm$ $18 \%$ respectively), which was further decreased during combined HYP-COL (66 $\pm 13 \%)$ and HYP-HOT ( $66 \pm 17 \%$ ) showing no interaction ( $p=0.5 \& 0.1$ respectively). Volitional (central) fatigue declined with time $(p<0.05)$, but was not significantly affected by condition. CONCLUSION: The results indicate that both temperature and hypoxia induce significant increases in the rate of muscle fatigue development. Additionally, fatigue is further increased when hypoxia and extreme ambient temperature are combined, however the effect is not interactive.

Accepted for Publication in: Medicine \& Science in Sports \& Exercise on 02/02/15

Published in: Medicine \& Science in Sports \& Exercise on 31/05/15

Full reference: Lloyd, A., Hodder, S. G., Raccuglia, M., \& Havenith, G. (2015). The Interaction Between Temperature And Hypoxia On The Rate Of Neuromuscular Fatigue Development. Medicine \& Science in Sports \& Exercise, 47(5S), 610. 